\title{
A wheat protein kinase gene TaSnRK2.9-5A associated with yield contributing traits
}

\author{
Shoaib Ur Rehman ${ }^{1}\left[\right.$ ] Jingyi Wang ${ }^{1} \cdot$ Xiaoping Chang $^{1} \cdot$ Xueyong Zhang ${ }^{1} \cdot$ Xinguo Mao $^{1} \cdot$ Ruilian Jing $^{1}$
}

Received: 18 May 2018 / Accepted: 22 November 2018 / Published online: 5 December 2018

(c) The Author(s) 2018

\begin{abstract}
Key message We developed breeder-friendly high-throughput and cost-effective KASP marker for marker-assisted selection for grain yield related traits in wheat.

Abstract Plant-specific protein kinase, SnRK2s, is a major family of signaling genes associated with metabolic regulations, nutrient utilization and response to external stimuli. In the present study, three copies of TaSnRK2.9 were isolated from chromosomes 5A, 5B and 5D of wheat (Triticum aestivum L.). The coding regions of TaSnRK2.9-5A, TaSnRK2.9-5B and promoter region of TaSnRK2.9-5D were investigated for sequence polymorphism. Single nucleotide polymorphisms (SNPs) were identified for TaSnRK2.9-5A, while no polymorphism was identified in TaSnRK2.9-5B and TaSnRK2.9-5D. The nucleotide sequence of TaSnRK2.9-5A consisted of 2180 bp having eight introns and nine exons. Three SNPs were identified at $308 \mathrm{nt}, 698 \mathrm{nt}$ and $1700 \mathrm{nt}$. For high-throughput genotyping, two kompetitive allele-specific PCR (KASP) markers were developed. Four haplotypes Hap-5A-1, Hap-5A-2, Hap-5A-3 and Hap-5A-4 were detected in wheat populations collected from China, Europe and Pakistan. Association analysis was performed with mixed linear model in TASSEL (v 5.0). The results indicated that Hap-5A-1/2 of TaSnRK2.9-5A were significantly associated with high thousand kernel weight, while Hap-5A-4 with high grains per spike. Overexpressing transgenic rice also showed higher grains per spike which is in accordance with association analysis results. Geographic distribution and allelic frequency indicted that the favored haplotypes were positively selected in Chinese (Hap-5A-1/2), Pakistani (Hap-5A-1), east European (Hap-5A-1) and west European (Hap-5A-4) wheat breeding. The results suggest that the developed KASP markers can be utilized in yield improvement by marker-assisted selection in wheat breeding.
\end{abstract}

\section{Introduction}

Crop productivity is limited by diverse climatic fluctuations including drought, extreme temperatures (cold and heat), and water logging. Breeding for stress resilient crop varieties is vital to sustain productivity of food commodities.

Communicated by Ian D Godwin.

Electronic supplementary material The online version of this article (https://doi.org/10.1007/s00122-018-3247-7) contains supplementary material, which is available to authorized users.

Xinguo Mao

maoxinguo@caas.cn

Ruilian Jing

jingruilian@caas.cn

1 National Key Facility for Crop Gene Resources and Genetic Improvement, Institute of Crop Sciences, Chinese Academy of Agricultural Sciences, Beijing 100081, China
A comprehensive understanding of gene networks underlying important adaptive traits showing resilience to weather extremes would benefit breeding for new cultivars (Mickelbart et al. 2015). Common wheat (Triticum aestivum L.) is the staple food of more than 4.5 billion people in 94 developing countries (Braun et al. 2010), and doubling the wheat production by 2050 due to population surge in the face of climate change and continuously declining arable land is a big challenge ( $\mathrm{Li}$ et al. 2018). Therefore, breeding for high grain yield is the utmost objective and there is continuous search for genes underpinning yield and its direct contributing traits.

Wheat grain yield per unit area is the product of grain weight and grain number per unit area (Reynolds et al. 2009; Sreenivasulu and Schnurbusch 2012). Variable correlations between grains per spike (GPS) and thousand kernel weight (TKW) have been reported. In bi-parental populations, significantly negative correlation has been reported between the two traits (Kuchel et al. 2007; Mcintyre et al. 2010; Wu et al. 
2012). Whereas, non-significant correlation was also identified for GPS and TKW in French winter wheat collections (Brancourt-Hulmel et al. 2003), CIMMYT-derived spring wheat collection (Maqbool et al. 2010) and Chinese landraces (Zhang et al. 2012a). However, a significant positive correlation has also been reported between GPS and TKW in Chinese modern cultivars (Zhang et al. 2012a). Several causal genes for grain traits including TKW and grain number have been cloned and their functional markers (FMs) have been developed including TaSnRK2.3-1A/1B (Miao et al. 2017), TaSnRK2.10-4A (Zhang et al. 2017), TaFlo2-A1 (Sajjad et al. 2017), TaTGW6-Al (Hanif et al. 2016), TaGS5$3 A$ (Ma et al. 2016), TaCwi-Al (Ma et al. 2012), TaSus2$2 B$ (Jiang et al. 2011), TaGW2 (Su et al. 2011), TaCKX6Dl (Zhang et al. 2012b), TaSAPl-Al (Chang et al. 2013), TaGSla (Guo et al. 2013), TaGS-DI (Zhang et al. 2014) and TaGASR7-Al (Dong et al. 2014).

Gel-based markers may be less suitable for genotyping a few SNPs on tens of thousands of plants, because they are cost-ineffective. In such cases, cost-effective genotyping platform such as Kompetitive Allele-Specific PCR (KASP) will be more effective and suitable for marker-assisted selection. Single-plex KASP assays offer high-throughput genotyping that is appropriate to screen thousands of genotypes in days with low cost per sample, minimum error rates, and quick turnaround.

Reversible phosphorylation of protein is the main theme in cell signaling involved in abiotic and biotic stress adaptation (Lata et al. 2015). At present, several protein kinase families have been reported involved in response to abiotic stresses. Calcium-dependent protein kinase (CDPK) (Ludwig et al. 2003), mitogen activated protein kinase (MAPK) (Wrzaczek and Hirt 2001) and sucrose non-fermenting 1 (SNF1)-related protein kinase (SnRK) (Hardie 2007) are the main stress-inducible protein kinases families. Recently, SnRK2s attracted much more attention because of its roles in seed dormancy, development and various environmental signaling (Coello et al. 2011).

On the basis of sequence similarity, expression pattern and gene structure, SnRK family is grouped into three subfamilies in plants, i.e., SnRK1, SnRK2 and SnRK3 (Hrabak et al. 2003). SnRK1 plays crucial role in sucrose signaling and carbon metabolism in plants, while SnRK2 and SnRK3 are involved in responses to abiotic stresses (Halford and Hey 2009). SnRK2 are plant-specific canonical serine/threonine protein kinases, having $\mathrm{N}$-terminal catalytic domain involved in kinase activation and a regulatory $\mathrm{C}$-terminal domain involved in protein-protein interaction and possibly in ABA and signaling (Vlad et al. 2009). The C-terminal domain is relatively shorter and is abundant in Asp/Glu and is predicted to be coiled-coil (Vlad et al. 2009). According to varied activation patterns in response to $\mathrm{ABA}$, and protein structure, SnRK2s are further divided into three sub-classes, namely subclass I, II and III, having no, weak and strong response to ABA, respectively (Kulik et al. 2011).

To date, SnRK2s are mainly reported for their involvement in response to abiotic stresses (Zhang et al. 2011a). Increasing evidence reveals that SnRK2s have also acquired various regulatory properties in growth and developmental processes in crop plants (Boudsocq et al. 2004; Mao et al. 2010). Gene mapping results showed that $\operatorname{TaSnRK2.7-B\text {was}}$ co-located in the same or adjacent chromosome intervals with QTLs for phosphorus utilization efficiency and accumulation efficiency of stem water-soluble carbohydrates (Zhang et al. 2011a, b), and TaSnRK2.3 co-located with a quantitative trait locus controlling total root length and plant height (Tian et al. 2013). Association analyses have confirmed that TaSnRK2.3-1A and TaSnRK2.3-1B, as well as the haplotypes of TaSnRK2.10-4A involved in regulation of TKW (Miao et al. 2017; Wang et al. 2014). Previous findings related to gene expression analysis from our group suggested that TaSnRK2.9 was highly sensitive to osmotic stress because this stressor strongly induced transcription within $1 \mathrm{~h}$ of exposure and generally caused highest level of transcription compared to other stressors (Zhang et al. 2016). In this study, TaSnRK2.9s were isolated and their sequence polymorphisms were assayed for developing functional markers. Breeder-friendly high-throughput KASP markers were developed. Association analysis was performed to reveal the association of haplotypes with yield-related traits. Geographic distribution of haplotypes was also investigated among wheat cultivars and landraces from China, Pakistan and Europe.

\section{Materials and methods}

\section{Wheat plant material and phenotyping}

A drought tolerant cultivar "Hanxuan 10" was used to isolate the coding and promoter sequence of TaSnRK2.9. A panel of 34 highly diverse wheat accessions was used to identify DNA sequence polymorphism of target genes. Three natural populations (NP) of common wheat were used for association analysis. Natural population 1 (NP-1) consisted of 323 winter wheat accessions, of which 318 were collected from China (12 landraces, 36 advanced lines, and 270 modern cultivars), mainly under cultivation in Yellow and Huai River Valleys Facultative Wheat Zone and Northern Winter Wheat Zone. The remaining 5 accessions were Early Premium, Triumph, Lovrin 10, Salgemma and Drysdale from America, Rumania, Italy and Australia, respectively. Natural population 2 (NP-2) comprised of 157 landraces, and natural population 3 (NP-3) consisted of 348 modern cultivars. Both NP-2 and NP-3 came from Chinese wheat core collection (Zhang et al. 2002). The NP-2 represents more than $70 \%$ of 
the total genetic diversity of the Chinese wheat germplasm collection (Hao et al. 2008, 2010). The NP-3 was used to identify progressive haplotypes and geographic distributions of favored and unfavored haplotypes of TaSnRK2.9-5A. In addition, 75 Pakistani and 313 European wheat cultivars were also surveyed to investigate the geographic distribution of TaSnRK2.9-5A haplotypes in these two regions.

NP-1 was planted in 10 different environments (year $\times$ site $\times$ water regime $\times$ heat stress) in Changping $\left(40^{\circ} 13^{\prime} \mathrm{N} ; 116^{\circ} 13^{\prime} \mathrm{E}\right)$, Beijing, in 2014-2015 and 2015-2016, and Shunyi ( $\left.40^{\circ} 23^{\prime} \mathrm{N} ; 116^{\circ} 56^{\prime} \mathrm{E}\right)$, Beijing, 2015-2016. Field experiments were carried out under drought-stressed (D), drought-heat-stressed (DH), well-watered (WW), and wellirrigated heat-stressed (WH) experimental units. Thermal stress shelters were built at flowering stage by covering plastic film on steel frames over the trail plots, which was installed before sowing. During the heat stress period, the average highest temperature outside the shelters was $35^{\circ} \mathrm{C}$; the average high temperature inside the shelters under drought stress condition was $45^{\circ} \mathrm{C}$, whereas in the shelters with WW conditions the temperature was $42^{\circ} \mathrm{C}$. The " $\mathrm{D}$ " experimental units were rain-fed. The rainfalls in the two growing seasons were $161 \mathrm{~mm}$ and $173 \mathrm{~mm}$, respectively. And precipitations mainly occurred in May and June at the experimental stations. Water contents of different soil profiles were measured at booting and grain-filling stages for each growth season (Table S1). The "WW" experimental units were irrigated with $750 \mathrm{~m}^{3} \mathrm{ha}^{-1}(75 \mathrm{~mm})$ at each of pre-overwintering, booting, flowering and grain-filling stages when the amounts of rainfall were insufficient during each corresponding period. Each experimental plot was $2 \mathrm{~m}$ length with 4 rows and row spacing of $30 \mathrm{~cm}, 40$ seeds per row. The wheat accessions were sown in the beginning of October, and harvested in the middle of June of the following year. NP-1 was planted for measurement of agronomic traits, such as plant height (PH), spikes per plant (SPP), spikelet number per plant (SNPS), GPS, TKW and yield per plant (YPP).

\section{Cloning TaSnRK2.9 in wheat and generation of transgenic rice plant material}

OSSAPK 9 cDNA sequence was blasted in wheat EST database. A consensus contig was obtained and a pair of primers (cDNA F/R) was designed to amplify wheat cDNA induced by PEG-treatment (Two-leaf hydroponic wheat seedlings of Hanxuan 10 were exposed to - 0.5 MPa PEG6000) (Table 1). TaSnRK2.9 cDNA was amplified by using $p f u$ DNA polymerase, and the target fragments were then ligated with $p E A S Y$-Blunt cloning vector. After sequencing, two endonuclease enzyme cutting sites for BamHI and SpeI, were added to upstream and downstream of the ORF, respectively, and a 30 bp MYC-tag sequence was inserted between BamHI site and the first ATG of TaSnRK2.9, followed by sub-cloning into binary vector pCAMBIA1391 cut with corresponding enzymes.

After the transformation of target gene into Agrobacteria EHA105, the construct was transferred into wild-type (WT) rice (Kittakee) by Agrobacteria-mediated method. Positive transgenic plants were initially screened by PCR, and then reconfirmed by sequencing. T3 pure lines were used for phenotyping analysis, and the expression level of target gene was identified by qRT-PCR, in triplicate with Roche LightCycler 96-well Real-Time PCR system (Roche, Switzerland) using SYBR Green PCR Master Mix Kit (Takara, Japan). Rice Tubulin was used as an internal control to quantify the relative transcript level of wheat target genes (Table 1). Thermal cycling conditions were pre-incubated at $95^{\circ} \mathrm{C}$ for 2 min, followed by $95^{\circ} \mathrm{C}$ for $10 \mathrm{~s}, 60^{\circ} \mathrm{C}$ for $30 \mathrm{~s}$, and $72{ }^{\circ} \mathrm{C}$ for $30 \mathrm{~s}$ for 45 cycles. The relative transcription level for each gene was calculated using $2^{-\Delta \Delta C T}$ method (Livak and Schmittgen 2001) (Table 1). WT and transgenic rice lines were planted at the Institute of Crop Sciences, Experimental Station in Beijing $\left(39^{\circ} 48^{\prime} \mathrm{N} ; 116^{\circ} 28^{\prime} \mathrm{E}\right)$. Rice seeds were germinated in water for 4 days followed by transplantation in plastic containers (Length $\times$ width $\times$ height $=80 \times 35 \times 3$ $0 \mathrm{~cm}$ ) in the middle of June 2017. This experiment was performed in randomized complete block design with three replications. The agronomic traits including plant height $(\mathrm{PH})$, spike length (SPL), number of fertile tillers (NFT), GPS and TKW were measured at maturity. To measure agronomical traits of transgenic rice, 27 plants were sowed in uniform tank containing the same amount of soil, and the management practices for WT and transgenic lines was same.

\section{Chromosomal location}

To identify the chromosomal location of target genes, the genomic sequences were used as queries to do BLAST online (https://urgi.versailles.inra.fr/blast/blast.php). Chromosomal location was further tested by PCR amplification in diploid, tetraploid, hexaploid wheat species and nullitetrasomic and ditelosomic lines of Chinese Spring using Ta5A1-F/R primers.

\section{Isolation and sequencing of TaSnRK2.9}

DNA of 34 highly polymorphic wheat accessions ( $\mathrm{Li}$ et al. 2016) was extracted from young leaves with CTAB method (Stewart and Via 1993). A pair of primers (AB-F/R) was selected to amplify the genomic sequence of TaSnRK2.9 in $\mathrm{A}$ and $\mathrm{B}$ genomes of wheat. A pair of primers (D-F/R) was also designed to amplify the promoter region of $T a S$ $n R K 2.9$ in D genome (Table 1). TransStart Fast Pfu DNA polymerase: $\mathrm{LA}-\mathrm{Taq}=1: 1$ was used for PCR amplification. PCR was performed in a total volume of $20 \mu \mathrm{L}$ having 
Table 1 Primers used in the experiments

\begin{tabular}{|c|c|c|}
\hline Primer name & Primer sequence $5^{\prime}$ to $3^{\prime}$ & Purpose \\
\hline cDNA-F/R & $\begin{array}{l}\text { F: GCGAGCGAGAGAGATAAGG } \\
\text { R: ACTCAAGTAGTAGCCTGAATAC }\end{array}$ & cDNA amplification \\
\hline Sub-cloning primers & $\begin{array}{l}\text { F: CTggtaccATGGAGCAGAAACTCATCTCTGAAGAGGATATG } \\
\text { GAGAGGGGGCCGG } \\
\text { R: CTactagtCTACATGGCGTATACTATCTCCCCG }\end{array}$ & Sub-cloning in binary vector \\
\hline qRT-PCR-F/R & $\begin{array}{l}\text { F: CGACGAGGCTCGCTTCTTTT } \\
\text { R: CCCACAGTTGACTTTGGTTGA }\end{array}$ & Gene expression level detection in transgenic rice \\
\hline Tubulin & $\begin{array}{l}\text { F: TGAGGACTGGTGCTTACCGC } \\
\text { R: GCACCATCAAACCTCAGGGA }\end{array}$ & Internal control qRT-PCR primers \\
\hline $\mathrm{AB}-\mathrm{F} / \mathrm{R}$ & $\begin{array}{l}\text { F: GCGGGGATCTCCGTGTC } \\
\text { R: TGCACATACAGATATTCACAGGTT }\end{array}$ & Genomic fragment amplification \\
\hline $\mathrm{D}-\mathrm{F} / \mathrm{R}$ & $\begin{array}{l}\text { F: GGAGAAGAGGCACCAAGAACAG } \\
\text { R: CGCCCTCTCTCCTTATCTCTC }\end{array}$ & D promoter region amplification \\
\hline $\begin{array}{l}\text { Seq-A-F1 } \\
\text { Seq-D-F1 }\end{array}$ & $\begin{array}{l}\text { F: CGACGCATCTCGCCATC } \\
\text { F: GCTGAACTTAAAAGCCCCC }\end{array}$ & Sequencing primers for $T a S n R K 2.9$ \\
\hline M13 & $\begin{array}{l}\text { F: TGTAAAACGACGGCCAGT } \\
\text { R: CAGGAAACAGCTATGACC }\end{array}$ & \\
\hline Ta5A1-F/R & $\begin{array}{l}\text { F: GCTGAGTGATGTGCCGGTG } \\
\text { R: TCGTAGTAATTTTCACTCACCTCCTT }\end{array}$ & Chromosomal location check \\
\hline KASP1 & $\begin{array}{l}\text { F: GAAGGTGACCAAGTTCATGCTCTTGGCACCAGACCAGAG } \\
\text { CCACGGC } \\
\text { F: GAAGGTCGGAGTCAACGGATTCTTGGCACCAGACCAGAG } \\
\text { CCACGGT } \\
\text { R: ACGCATCATCAAACTTGTAAATACC }\end{array}$ & KASP assay for SNP at $308 \mathrm{nt}(\mathrm{C} / \mathrm{T})$ \\
\hline KASP2 & $\begin{array}{l}\text { R: GAAGGTGACCAAGTTCATGCTTGAATGTAGTCCGGAATC } \\
\text { GAGTACG } \\
\text { R: GAAGGTCGGAGTCAACGGATTTGAATGTAGTCCGGAATC } \\
\text { GAGTACT } \\
\text { F: CCGAGCTCAACTTTTTCAGAAAA }\end{array}$ & KASP assay for SNP at $1700 \mathrm{nt}(\mathrm{A} / \mathrm{C})$ \\
\hline
\end{tabular}

Small caps italic letters show BamHI (ggtacc) and SpeI (actagt) sites. Underlined letters show 30-bp MYC-tag sequence

$4 \mu \mathrm{L} 5 \times$ Pfu buffer, $0.4 \mu \mathrm{L} P f u+\mathrm{LA}$-Taq mixture, $0.2 \mu \mathrm{L}$ dNTP ( $25 \mathrm{mM}$ for each nucleotide), 1.2/1.2 $\mu \mathrm{L}$ forward and reverse primer $(10 \mu \mathrm{M}), 2.2 \mu \mathrm{L}$ DNA $\left(100 \mathrm{ng} \mu \mathrm{L}^{-1}\right)$,

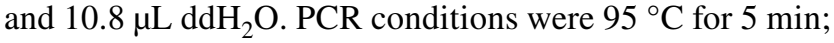
34 cycles of $95{ }^{\circ} \mathrm{C}$ for $1 \mathrm{~min}, 59{ }^{\circ} \mathrm{C}$ for $40 \mathrm{~s}, 72{ }^{\circ} \mathrm{C}$ for $3 \mathrm{~min}$; followed by a final extension of $72{ }^{\circ} \mathrm{C}$ for $10 \mathrm{~min}$. PCR product was checked on agarose gel (1.2\%), and desired band was isolated and extracted using BioTeke DNA extraction kit, followed by cloning into $p E A S Y$ Blunt vector. Twenty-four positive clones for each sample were selected for sequencing by DNA Analyzer 3730XL. To get the full-length desired sequence of TaSnRK2.9-5A and TaSnRK2.9-5B, M13 forward and reverse primers and an overlapping sequencing primer (Seq-A-F1) were used for sequence walking. For D genome promoter region sequencing, ten positive clones were sequenced with M13 forward and reverse and an overlapping sequencing primer (Seq-D-F1) (Table 1). The sequence of each clone was obtained by assembling with SeqMan program in DNAStar software package. The genomic origin of each sequence was firstly confirmed by comparing with reference genomic sequence obtained from URGI (https ://urgi.versailles.inra.fr/blast/blast.php).

\section{Functional marker development}

For high-throughput genotyping, KASP primers were developed on the two SNP sites (KASP1 at 308 nt and KASP2 at $1700 \mathrm{nt}$ in A genome) by following standard KASP guidelines (http://www.lgcgenomics.com. The allele-specific primers were developed having the standard FAM ( $5^{\prime}$ GAA GGTGACCAAGTTCATGCT 3') and HEX (5' GAAGGT CGGAGTCAACGGATT 3') tails with a targeted SNP at the $3^{\prime}$ end (Table 1). For KASP1, two forward primers (allele specific) and one common reverse primer was designed. However for KASP2, two reverse primers (allele specific) and one common forward primer was designed. A common primer was designed so that the total fragment length was less than $120 \mathrm{bp}$. KASP makers were then applied across the entire NP-1, NP-2, NP-3, Pakistani and European wheat accessions. The PCR mixture consisted $30 \mu \mathrm{L}$ common primer $(100 \mu \mathrm{M}), 12 \mu \mathrm{L}$ of each tailed primer $(100 \mu \mathrm{M})$, and $46 \mu \mathrm{L} \mathrm{ddH}_{2} \mathrm{O}$. Assays were tested in $\sim 4 \mu \mathrm{L}$ reaction 
mixture $(50 \mathrm{ng} / \mu \mathrm{L}$ DNA, $2.5 \mu \mathrm{L}$ of $1 \times$ KASP master mixture, $0.04 \mu \mathrm{L} \mathrm{MgCl}_{2}, 0.056 \mu \mathrm{L}$ primer mixture (all three

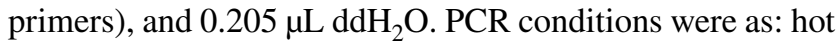
start at $95{ }^{\circ} \mathrm{C}$ for $15 \mathrm{~min}$, followed by 10 touch down cycles $\left(95{ }^{\circ} \mathrm{C}\right.$ for $20 \mathrm{~s}$; touch down at $65^{\circ} \mathrm{C}$ initially and decreasing by $-1{ }^{\circ} \mathrm{C}$ per cycle for $25 \mathrm{~s}$ ), followed by 30 more cycles of annealing $\left(95^{\circ} \mathrm{C}\right.$ for $10 \mathrm{~s} ; 57^{\circ} \mathrm{C}$ for $\left.60 \mathrm{~s}\right)$. An extension step did not performed as the fragment lengths were less than $120 \mathrm{bp}$. Fluorescence levels were detected by Synergy H1MF Microplate Reader (BioTek Instruments, Inc, USA) by following the manufacturer's guide and analyzed using KLUSTERCALLER software (version 3.4.1.36; LGC Hoddesdon, UK).

\section{Association analysis}

Descriptive statistics and estimates of variance were conducted using Microsoft Excel 2013. TASSEL (v 5.0) was used to identify significant associations between agronomic traits and haplotypes for NP-1. Mixed linear model (MLM) was executed using population structure $(\mathrm{Q})$ and kinship (K) matrix to control spurious associations. Associations were considered statistically significant at $P<0.05$. The effects of haplotype on each trait were also analyzed by Student's t test at $P<0.05$ (even 0.01).

\section{Results}

\section{Genetic characterization of TaSnRK2.9}

BLAST results showed that TaSnRK2.9 was located on chromosome $5 \mathrm{~A}, 5 \mathrm{~B}$ and $5 \mathrm{D}$, and were named as TaSnRK2.9-5A, TaSnRK2.9-5B and TaSnRK2.9-5D, accordingly. Gene structure showed that TaSnRK2.9 was consisted of 9 exons and 8 introns. Additionally, the promoter region for TaSnRK2.9-5D gene was also isolated, and named as TaSnRK2.9-5D-PRO. The fragment sizes of TaSnRK2.9-5A, TaSnRK2.9-5B, and TaSnRK2.9-5D-PRO were 2180,2137 , and $2200 \mathrm{bp}$, respectively.

To further determine the chromosomal location of $\mathrm{TaS}$ $n R K 2.9$, a pair of genome specific primer (Ta5A1-F/R) for TaSnRK2.9-5A was designed. The amplified fragment was $380 \mathrm{bp}$ in length. As shown in Fig. 1, the amplified fragment was identified only in species carrying " $A$ " genome. This was further confirmed by PCR amplification in nulli-tetrasomic and ditelosomic lines of Chinese Spring, revealing that TaSnRK2.9-5A was located on the short arm of chromosome 5A (Fig. 1).

\section{Sequence polymorphism assays and marker development}

For TaSnRK2.9-5B coding and TaSnRK2.9-5D promoter region, no polymorphism was identified, hence were excluded from further analysis. For TaSnRK2.9-5A, polymorphic sites were identified in both intron and exon regions (Fig. 2a). The SNP at $308 \mathrm{nt}(\mathrm{C} / \mathrm{T})$ was identified in intron and caused no amino acid change. The SNP at $1700 \mathrm{nt}(\mathrm{A} / \mathrm{C})$ in exon led to an amino acid change $(\mathrm{CAG} \rightarrow \mathrm{Gln}$ to $\mathrm{CCG} \rightarrow$ Pro) without changing protein 3D structure (Supplementary Fig. 1). KASP markers were developed at the both SNP sites. KASP1 was developed for SNP at $308 \mathrm{nt}$, whereas KASP2 was developed for SNP at $1700 \mathrm{nt}$ (Fig. 2b, c). Scatter plot for KASP assay shows clustering of accessions on the $X$-(FAM) and $Y$ - (HEX) axes. Strong FAM signal results in clogging of blue dots (genotypes) at extreme right bottom while strong HEX signal results in clogging the red dots (genotypes) at extreme top left corner of the figure. For KASP1, accessions colored blue have "C" allele, while accessions colored red have "T" allele. For KASP2, accessions colored blue have "C" allele, whereas accessions colored red have "A" allele.

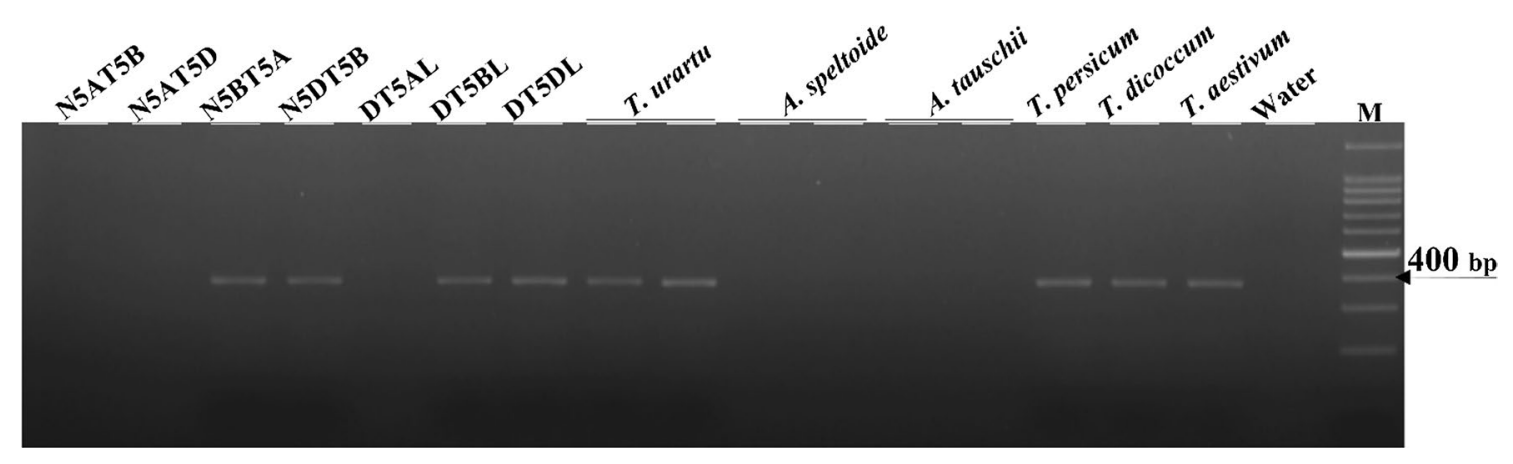

Fig. 1 Chromosomal location of TaSnRK2.9-5A. TaSnRK2.9-5A was located on chromosome 5A using nulli-tetrasomic and ditelosomic (DT) lines of Chinese Spring. M, DNA100 bp marker. T. urartu
(AA), A. speltoide (BB), A. tauschii (DD), T. persicum (AABB), $T$. dicoccum (AABB), T. aestivum (AABBDD) 


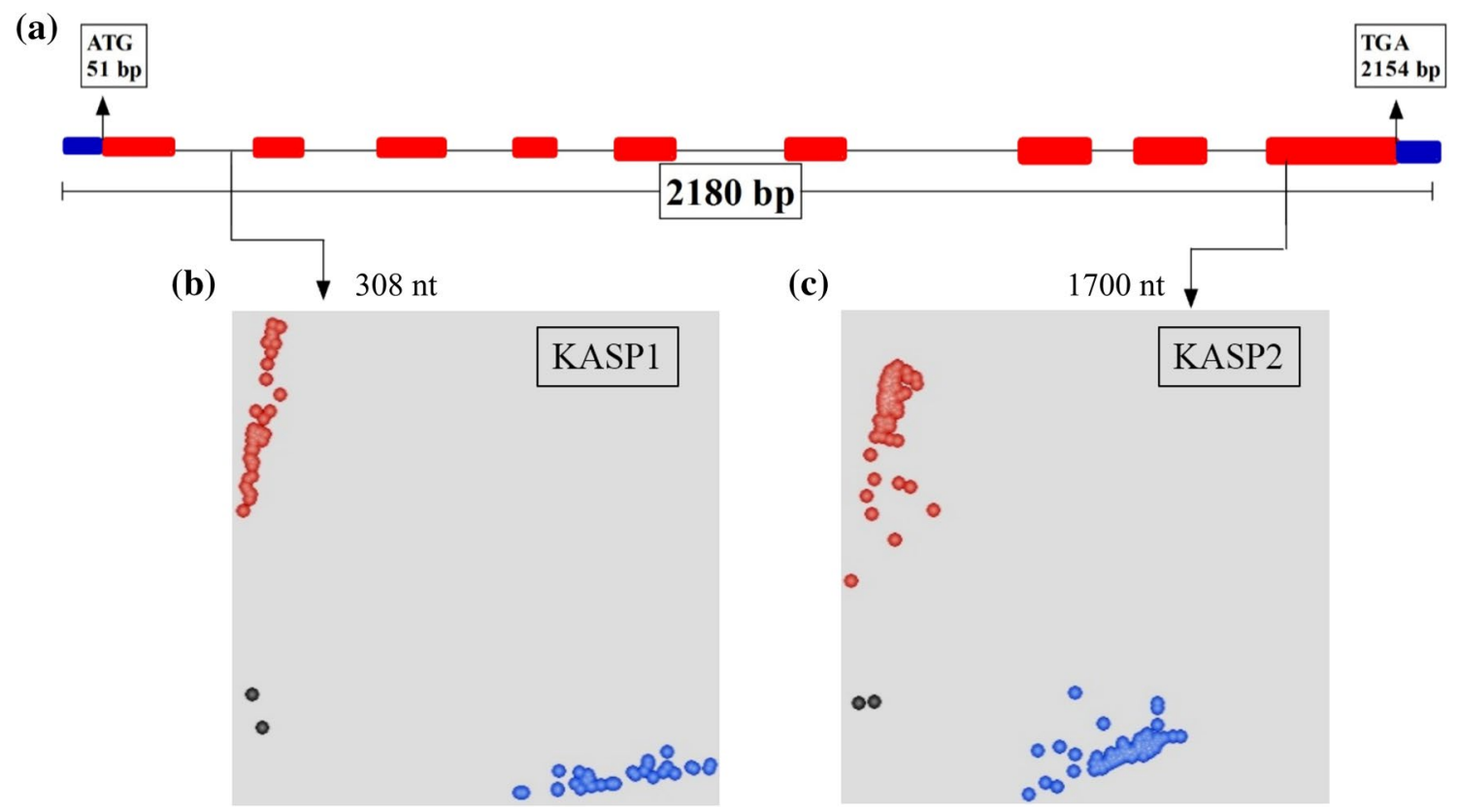

Fig. 2 Gene structure and functional marker development for TaSnRK2.9-5. a Gene structure, blue blocks $=$ untranslated region, red blocks $=$ exon, black line $=$ intron, $M=$ DNA marker $(100 \mathrm{bp})$. Scatter plot for KASP assays; showing clustering of accessions on the $X$ (FAM) and $Y$ - (HEX) axes. Accessions colored blue have the FAM-

\section{Association analysis of TaSnRK2.9-5A haplotypes and agronomic traits}

Four haplotypes of TaSnRK2.9-5A, i.e., Hap-5A-1 (TA), Hap-5A-2 (TC), Hap-5A-3 (CC) and Hap-5A-4 (CA) were identified in wheat population NP-1. Hap-5A-1 was the most frequent haplotype available in $54.8 \%$ accessions of NP-1, followed by Hap-5A-2 (22.5\%), Hap-5A-3 (17.3) and Hap5A-4 (5.2\%). Association analysis showed that an unie field sites, TaSnRK2.9-5A was associated with TKW in four

type allele; accessions colored red have the HEX-type allele; black dots represent the NTC (non-template control). b KASP1 assay for SNP-308 nt shows allele "C" in FAM and allele "T" in HEX cluster. c KASP2 assay for SNP-1700 nt shows allele " $\mathrm{C}$ " in FAM and allele "A" in HEX cluster

out of ten and GPS six out of ten environments (Table 2). Both Hap-5A-1 and Hap-5A-2 (Hap-5A-1/2) were favored haplotypes for higher TKW relative to Hap-5A-3/4 (Fig. 3a). Hap-5A-4 had significantly higher GPS compared to other haplotypes (Fig. 3b).

\section{Phenotyping of TaSnRK2.9-5A overexpressing rice}

Two rice transgenic lines for TaSnRK2.9-5A, with higher normalized fold expression (Fig. 4a), were used for
Table 2 Association of TaSnRK2.9-5A haplotypes with agronomic traits in individual environments in NP-1

\begin{tabular}{lllll}
\hline Environments & TKW $(P$ value $)$ & GPS $(P$ value $)$ & SPP $(P$ value $)$ & SNPS $(P$ value $)$ \\
\hline $2015-S Y-D$ & $0.039^{*}$ & NS & $0.016^{*}$ & NS \\
$2015-S Y-D H$ & NS & NS & NS & NS \\
$2015-S Y-W H$ & $0.011^{*}$ & $0.012^{*}$ & $0.019^{*}$ & NS \\
$2015-S Y-W$ & NS & $9.38 \mathrm{E}-04^{* * *}$ & NS & NS \\
$2016-S Y-D$ & $0.044^{*}$ & $0.001^{*}$ & $0.009^{* *}$ & $0.001^{* *}$ \\
$2016-S Y-D H$ & NS & $0.032^{*}$ & NS & NS \\
$2016-S Y-W H$ & NS & NS & NS & NS \\
$2016-S Y-W$ & NS & $0.019^{*}$ & NS & $0.003^{* *}$ \\
$2016-C P-D$ & $0.043^{*}$ & $0.040^{*}$ & NS & NS \\
$2016-C P-W$ & NS & NS & NS & NS \\
\hline
\end{tabular}

$T K W$ thousand kernel weight, GPS grains per spike, $S P P$ spikes per plant, $S N P S$ spikelet numbers per spike, $N S$ non-significant. $* P<0.05, * * P<0.01, * * * P<0.001$. The ten environments were at Shunyi (SY) and Changping (CP) under drought (D), drought + heat (DH), well-watered (W) and well-watered + heat (WH) conditions in 2015 and 2016 
(a) Hap-5A-1 Hap-5A-2 $\quad$ Hap-5A-3 Hap-5A-4

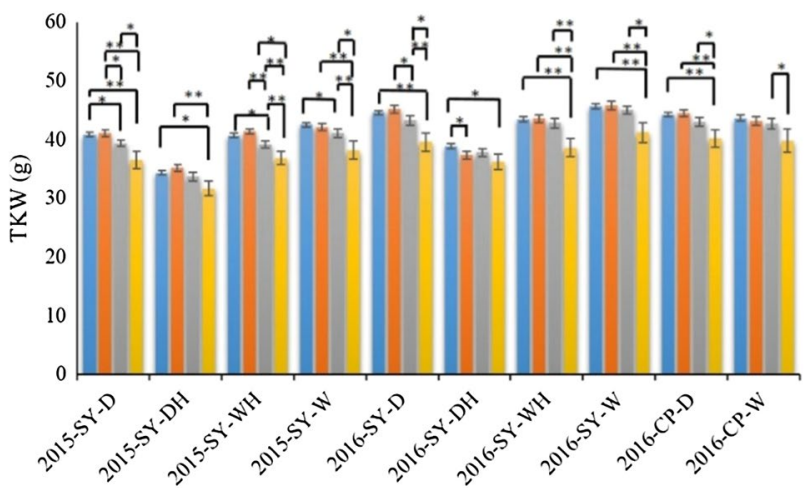

(b)

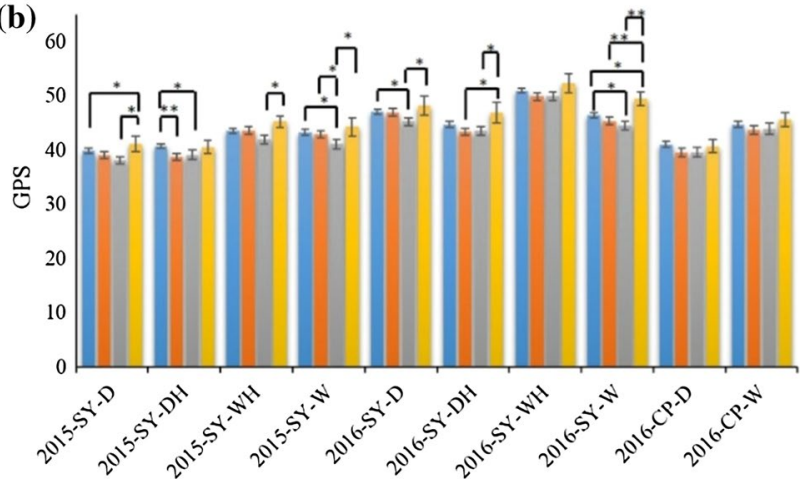

Fig. 3 Phenotypic comparison of four TaSnRK2.9-5A haplotypes in ten environments in NP-1. a Traits are thousand kernel weightTKW. b grains per spike-GPS. $* P<0.05, * * P<0.01$. Error bars denote SE

phenotyping. Data from six plants of each transgenic rice line and WT were averaged. Although both transgenic lines showed a significantly shorter $\mathrm{PH}$, but significant increments were observed for SPL and GPS compared with WT plants. As compared to WT, transgenic lines showed a significant reduction in $\mathrm{PH}$ from 88.0 to $82.8 \mathrm{~cm}$. Spike length increased from 12.3 to $13.5 \mathrm{~cm}$, and GPS increased from 78 to 87 . TKW showed slight reduction from 24.8 to $23.9 \mathrm{~g}$ (Fig. 4b, c).

\section{Geographic distribution of TaSnRK2.9-5A haplotypes in China, Pakistan and Europe}

Previous reports have revealed that the favored haplotypes gradually pyramid due to the crop improvement efforts (Barrero et al. 2011). To determine, whether the favored haplotypes for TaSnRK2.9-5A were selected in wheat breeding, we investigated the geographic distribution of TaSnRK2.95A in NP-2, NP-3, Pakistani and European wheat cultivars. China has three major wheat growing regions which were further divided into 10 agro-ecological zones (He et al. 2001). Zones I-IV are the major wheat producing zones based on production and cultivation area. In NP-2 (landraces), the frequency of the favored haplotypes Hap-5A-1/2 for TKW was low, and Hap-5A-3 was the pre-dominant haplotype in all major areas except three zones (Zone IV, V, and VIII) (Fig. 5a), suggesting that the selection pressure on haplotypes in different areas was not as strong as anticipated. In NP-3 (modern cultivars), the combined frequency of the two favored haplotypes (Hap-5A-1 and Hap-5A-2) was higher in the four major zones, i.e., Zones I-IV (Fig. 5b). The frequency of Hap-5A-1 increased remarkably from 22 to $48 \%$ in Zone I, 0 to $53 \%$ in Zone II, 0 to $45.8 \%$ in Zone III, and 0 to $42.5 \%$ in Zone IV from landraces to modern cultivars, respectively, while the frequency of Hap-5A-2 was reduced in Zone I from 22 to $14 \%$, and increased from 15.7 to $17.3 \%$ in Zone II, 4.3 to $20.8 \%$ in Zone III and 16 to $37.5 \%$ in Zone IV from landraces to modern cultivars, respectively. The results indicated that favored haplotypes experienced positive selection in Chinese wheat breeding programs.

Geographic distribution of TaSnRK2.9-5A haplotypes was also investigated among Pakistani and European (a)

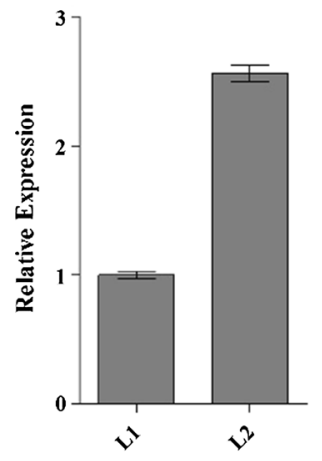

(b)

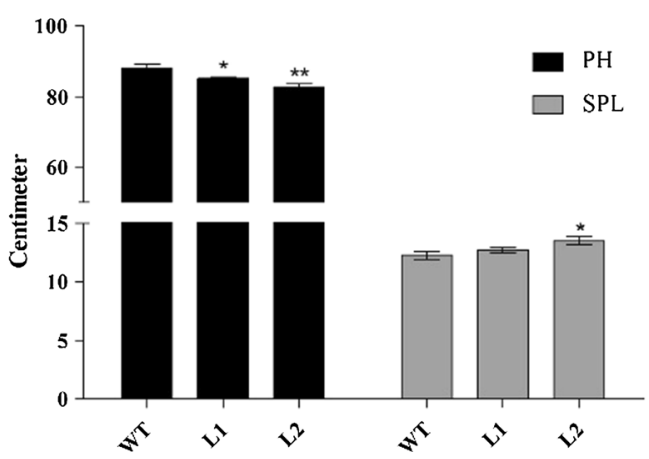

(c)



Fig. 4 Phenotypes of rice plants overexpressing TaSnRK2.9-5A. a Relative gene expression of transgenic rice. Comparison of traits in transgenic and control plants for (b), plant height $(\mathrm{PH})$ and spike length (SPL), and c number of fertile tillers (NFT), grains per spike (GPS) and thousand kernel weight (TKW). WT, wild type; L1, L2, transgenic lines. Error bars denote SE. $* P<0.05$, $* * P<0.01$ 
Fig. 5 Haplotype distribution of TaSnRK2.9-5A in China. a Chinese landraces. b modern cultivars in 10 major wheat production zones. I, Northern Winter Wheat Zone; II, Yellow and Huai River Valleys Cultivated Wheat Zone; III, Middle and Low Yangtze Valleys AutumnSown Spring Wheat Zone; IV, Southwestern AutumnSown Spring Wheat Zone; V, Southern Autumn-Sown Spring Wheat Zone; VI, Northeastern Spring Wheat Zone; VII, Northern Spring Wheat Zone; VIII, Northwestern Spring Wheat Zone; IX, Qinghai-Tibetan Plateau Spring-Winter Wheat Zone; X, Xinjiag Winter-Spring Wheat Zone. Size of pie chart is directly proportional to the number of accessions



(b)

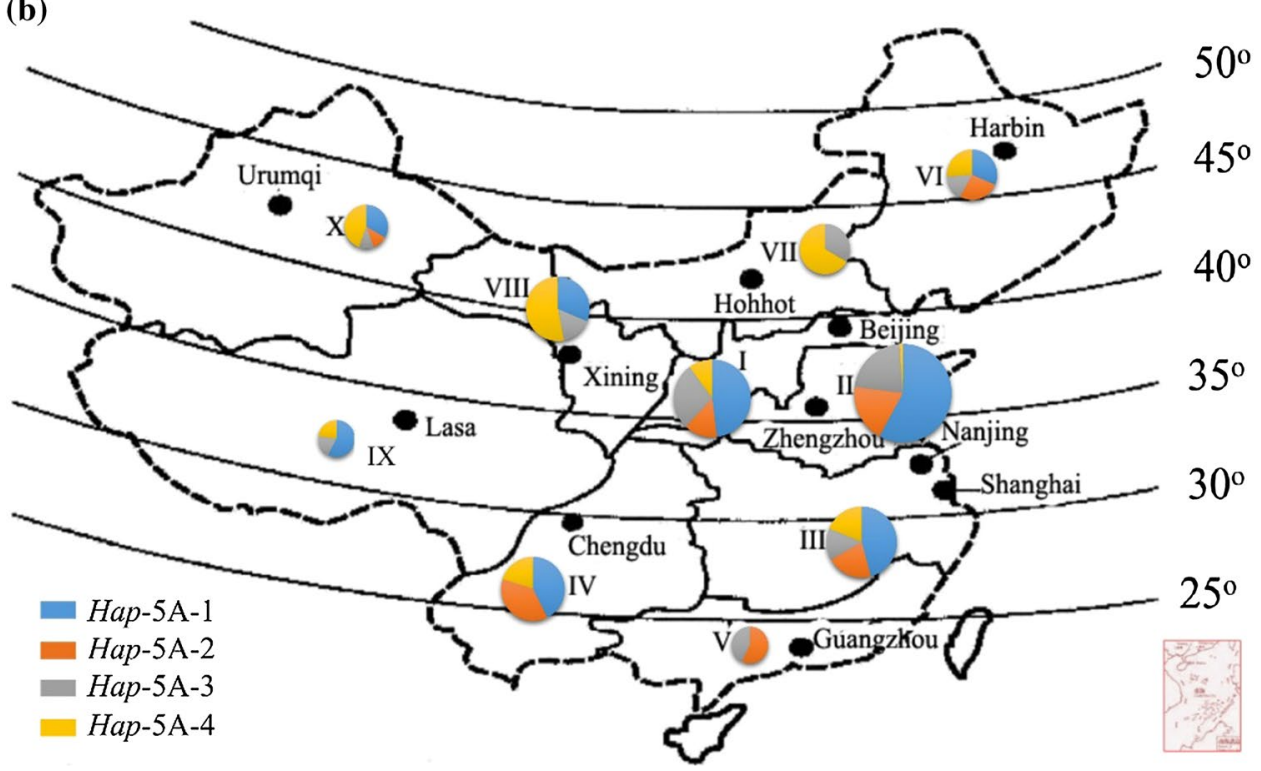

wheat accessions. The combined frequency of Hap-5A-1/2 among five different regions of Pakistan was 79.41\% (Punjab irrigated zone), 77.77\% (Punjab rain-fed zone), $70 \%$ (Sind), 88.23\% (Khyber Pakhtunkhwa) and 25\% (Balochistan) (Fig. 6). The frequencies of favored haplotypes for TKW and GPS were also higher among European wheat accessions (Fig. 7). The combined results demonstrated that Hap-5A-1/2 were the dominant haplotypes of TaSnRK2.9-5A in China and Pakistan, while Hap-5A-1/4 were the prominent haplotypes among European wheat cultivars and selection pressure on these haplotypes differed in degree among these regions.

\section{Positive selection of Hap-5A-1, Hap-5A-2 and Hap-5A-4 in China, Pakistan and European wheat breeding process}

On the basis of released time, NP-3 was subdivided into six groups, i.e., cultivars released before 1951, 1951-1960, 1961-1970, 1971-1980, 1981-1990 and 1991-2001. The frequency of haplotype Hap-5A-3 decreased from $40 \%$ before $1951-16.5 \%$ in $1991-2001$ era (Fig. 8). The frequency of Hap-5A-4 increased from $10 \%$ before 1951 to $23.3 \%$ in 1991-2001 (Fig. 8). The combined frequency of Hap-5A-1 and Hap-5A-2 continuously increased. From 1971 to onwards, the increase in combined frequency for 


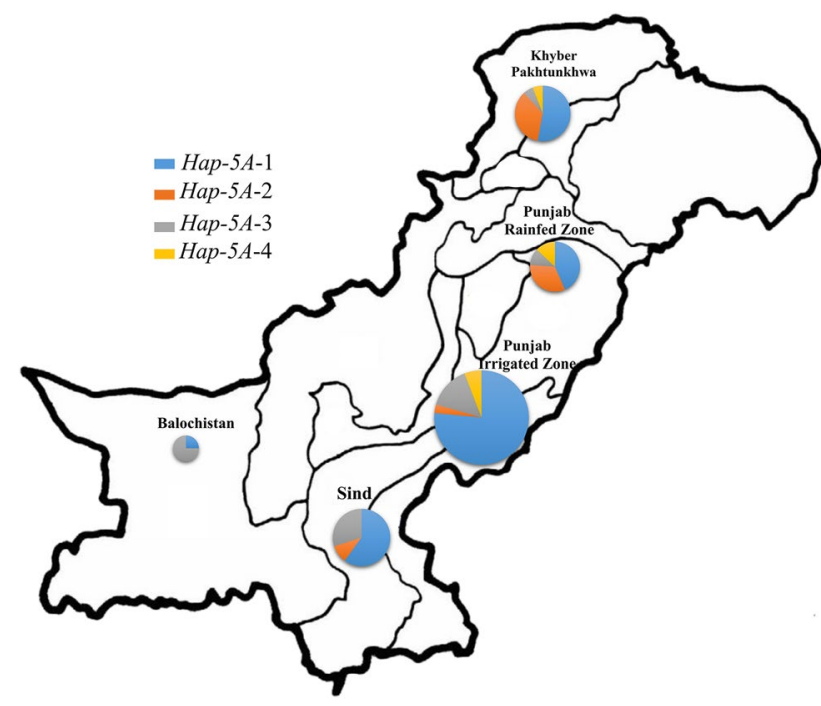

Fig. 6 Distribution of TaSnRK2.9-5A haplotypes among Pakistani wheat accessions. Size of pie chart is directly proportional to the number of accessions

Hap-5A-1/2 revealed a progressive selection (Fig. 8). In Pakistani accessions, a higher frequency for Hap-5A-1 was observed (Supplementary Fig. 2). The European population was subdivided into 11 groups according to released date, and the combined frequency of Hap-5A-1/2 remained higher followed by Hap-5A-4 (Supplementary Fig. 3).

\section{Discussion}

Plant breeding merely through phenotypic selection is relatively ineffective (Gedye et al. 2012), and efficient selections using molecular markers will accelerate the breeding process (Rasheed et al. 2017). Common wheat is an allohexaploid with a large genome size ( $17 \mathrm{~Gb})$ (Gupta et al. 2008) having polyploid nature and highly similar homologous genes. Genomic studies in wheat were reliant to some extent on comparative genomics approaches with other members of grass family courtesy high collinearity and genetic assembly among grass family members (Murat et al. 2014). At present, the release of reference genome assembly (http://www.wheat genome.org) has changed that, and paid a smooth way for gene cloning in wheat.

Wheat " $D$ " genome has a narrow genetic background, and the level of polymorphism is relatively small when compared to "A" and "B" genomes (Rasheed et al. 2018). Moreover, non-coding regions have relatively higher level

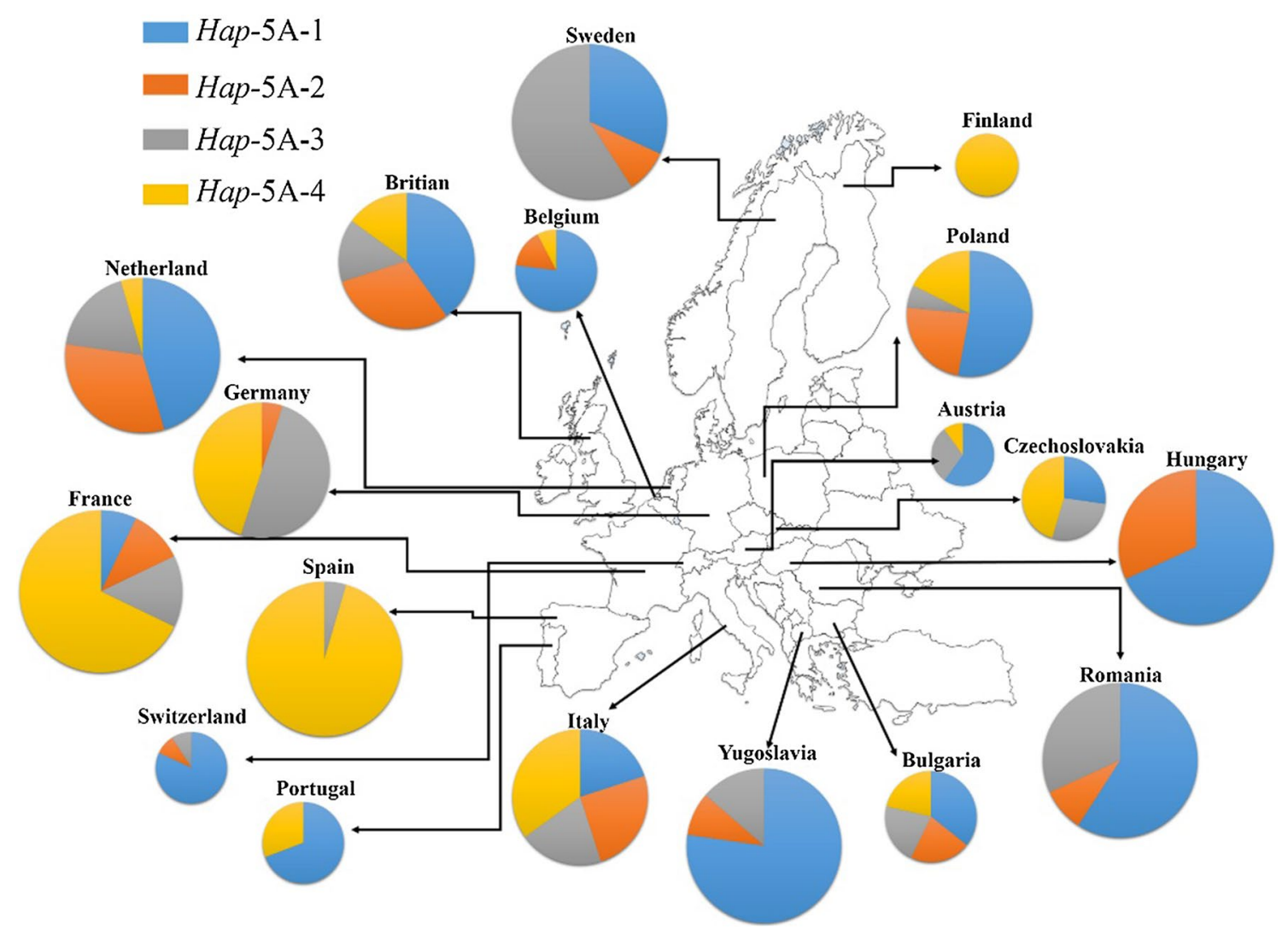

Fig. 7 Distribution of TaSnRK2.9-5A haplotypes among European wheat accessions. Size of pie chart is directly proportional to the number of accessions 
Fig. 8 Favored haplotypes were selected in Chinese wheat breeding (NP-3)

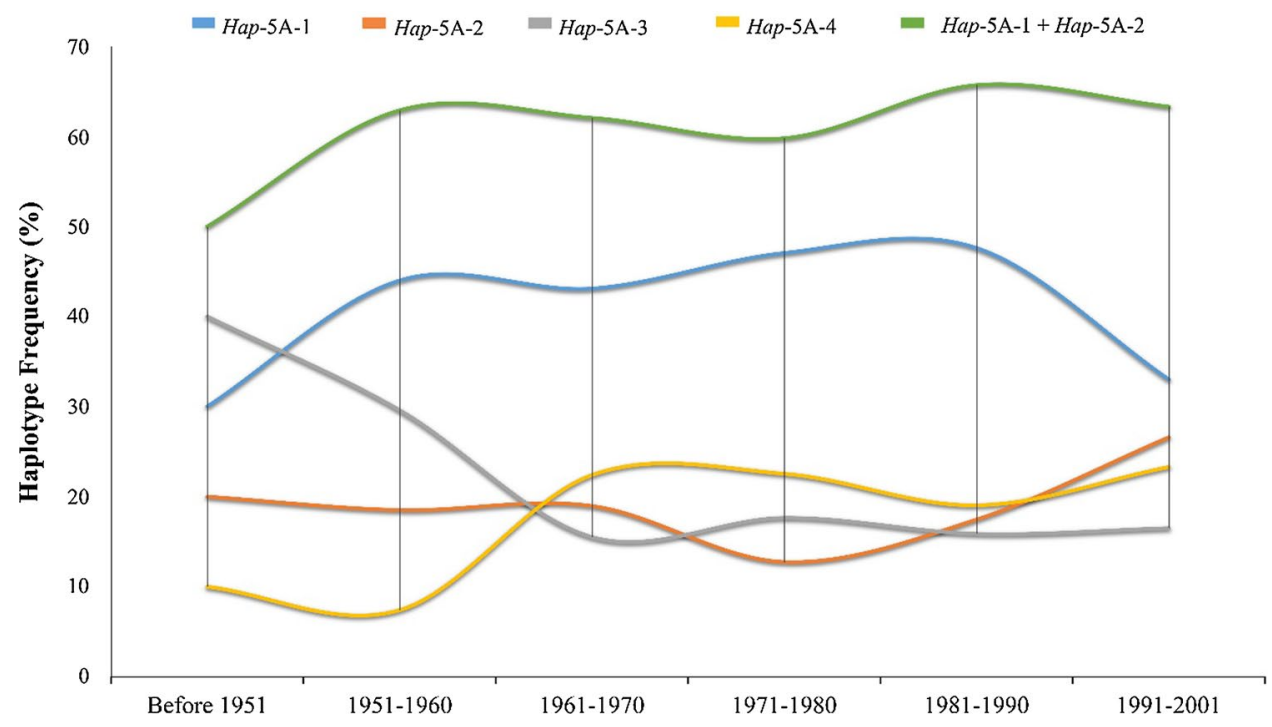

of polymorphism as compared to coding region (Nasu et al. 2002). The absence of polymorphism in TaSnRK2.9-5B coding and TaSnRK2.9-5D promoter region is probably due to the allele fixation during evolution and domestication or low genetic diversity in the panel used for polymorphism. More work is required to investigate these two probabilities in more diverse wheat accessions and progenitor species. For TaSnRK2.9-5A, SNP identified at 1700 bp was within the catalytic domain which led to an amino acid change, i.e., Gln237 to Pro237 but without protein structural alteration (Supplementary Fig. 1). Both glutamine and proline contain an $\alpha$-amino and $\alpha$-carboxylic group, and carry positive charge, which might be the reason for the unaltered structures of the two proteins.

Genetic gain in wheat is around $0.8-1.0 \%$ per year (Ray et al. 2012), for example, in France (Brancourt-Hulmel et al. 2003), Italy (Canevara et al. 1994), UK (Shearman et al. 2005) and China (Zhou et al. 2007a). The genetic gain has largely been achieved by improvements in grain number per square meter with a slight change in individual grain weight (Gaju et al. 2009). Accessions possessing Hap-5A-1/2 of TaSnRK2.9-5A had the higher TKW, while accessions possessing Hap-5A-4 had higher GPS. Yield-related traits of cereal crops are governed by multiple genes and are strongly influenced by abiotic factors (Zhang et al. 2013). Among the reported gene determinants of cereal grain traits, some genes can act constitutively under different conditions, while others function in particular environmental conditions (Dong et al. 2014). In this study, TKW showed significant association in all individual drought-stressed environmental conditions suggesting that the use of Hap-5A-1/2 could be instrumental for higher TKW selection in drought-stressed conditions. Moreover, high GPS in overexpressing TaSnRK2.9-5A rice lines might also be an attribute of Hap-5A-4 of TaSnRK2.9$5 \mathrm{~A}$. Higher grain yield has been a major objective of wheat breeders around the globe. In Northern China, $1.3 \%$ annual genetic gain for TKW has been achieved over last three decades with simultaneous increase in GPS in Yellow and Huai River Valleys Facultative Wheat Zone (Zhou et al. 2007a). Increase in TKW and kernel weight per spike was also reported in Southern China winter wheat region since 1949 (Zhou et al. 2007b).

From landraces to modern cultivars, the proportion of favored haplotypes increased suggesting a positive selection on TaSnRK2.9-5A during wheat breeding (Fig. 5a, b). For Hap-5A-1/2, the increase was more apparent in the major wheat production areas. For example, Zones I, II, and III which account for about $64.8 \%$ of total national wheat area in China and greater turnover of wheat cultivars were also reported from these Zones. Average TKW of varieties especially in Zone II is about 42-43 g (Barrero et al. 2011). In China, wheat yield increase has largely depended on higher GPS and TKW (Zhang et al. 2012a). The frequencies of Hap-5A-1/2 and Hap-5A-4 rose steadily from 1971 to onwards during that time Chinese wheat varieties underwent significant increase in grain yield. This increase may also reflect continuous selection of TKW and GPS for higher grain yield in China (Fig. 9). Given that the favored haplotypes of $T a S n R K 2.9-5 \mathrm{~A}$ were apparently selected in Chinese wheat breeding history, further selection of favored haplotypes might be helpful for continual improvement in wheat grain yield.

Wheat accessions from Pakistan and Europe were also used to evaluate TaSnRK2.9-5A in different geographical regions. In Pakistani accessions, although favored Hap-5A-1 (for TKW) was apparently selected in most areas from 1944 to 2016, the frequency of Hap-5A-4, the favored allele for GPS, remained very low, suggesting the potential of Hap-5A-4 introgression through FMs developed in this study (Fig. 6). The frequencies of favored 
Fig. 9 TKW and GPS changes in NP-3 over decades. Error bar indicates SE

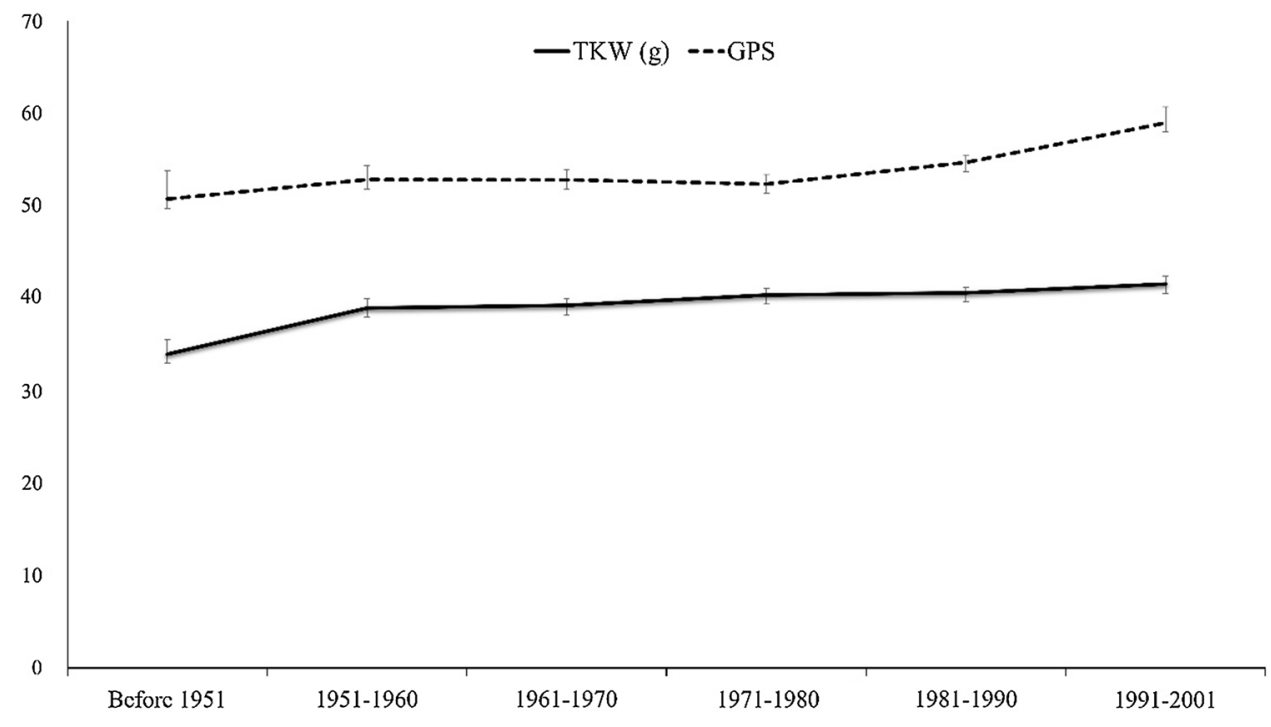

haplotypes were higher in European population. Hap$5 \mathrm{~A}-1 / 2$ are more dominant in East European countries, while Hap-5A-4 is more dominant in West European countries, indicating further increase is still feasible in the regions where the favored haplotypes remained at lower frequencies, such as Finland and Germany (for Hap-5A-1) and Sweden, Switzerland, Hungary, Romania and Yugoslavia (for Hap-5A-4) (Fig. 7). The probable reason for the lower frequencies in these regions might be attributed to their breeding strategies deployed for gaining higher yields.

In genome-wide association studies for TKW and GPS, many loci were found to be linked with only one of the parameters. The superior haplotypes at these loci should increase the phenotypic value of one parameter without negatively affecting the phenotypic value of the others (Zhang et al. 2012a). Thus, selection of such QTL was likely a key reason in altering the association between TKW and GPS over time. From the results of this study, selection of favored haplotypes (Hap-5A-4) would also be helpful to increase GPS without reduction in mean TKW in wheat (Fig. 9). Genes and their functions in governing TKW are still mainly unidentified (Sajjad et al. 2017). Further selection of superior alleles might be useful for continued improvement in wheat.

High-throughput genotyping is of utmost importance for use in marker-assisted selection and genomic selection (Semagn et al. 2014). Gel-free KASP assays could significantly improve speed and efficiency of the selection in wheat breeding programs. Utilization of these multiple FMs will be more effective for yield improvement and can be instrumental in enhancing additive genetic variation (Wang et al. 2012). The gene identified here and molecular markers developed to identify haplotypes are useful for markerassisted selection in breeding for TKW and GPS, which can be utilized alone or in combination with other functional markers.

Author contribution statement RJ, XM and SUR designed the experiments. SUR, JW, XC and XM performed the experiments. SUR analyzed the data. SUR, XM and RJ wrote the article. RJ and XM revised the article.

Acknowledgements The authors acknowledge Dr. Chenyang Hao (Institute of Crop Sciences, CAAS) for providing DNA samples of NP-2 (landraces) and NP-3 (modern cultivars) and European wheat accessions. The authors also acknowledge Dr. Awais Rasheed (Institute of Crop Science, CAAS) for giving DNA samples of Pakistani wheat accessions, help in developing KASP assays and suggestions on the article. This study was financially supported by The National Key Research and Development Plan (2016YFD0100102) of China, National Natural Science Foundation of China (31571660), and Agricultural Science and Technology Innovation Program (ASTIP).

\section{Compliance with ethical standards}

Conflict of interest On behalf of all authors, the corresponding author states that there is no conflict of interest.

Open Access This article is distributed under the terms of the Creative Commons Attribution 4.0 International License (http://creativeco mmons.org/licenses/by/4.0/), which permits unrestricted use, distribution, and reproduction in any medium, provided you give appropriate credit to the original author(s) and the source, provide a link to the Creative Commons license, and indicate if changes were made.

\section{References}

Barrero RA, Bellgard M, Zhang X (2011) Diverse approaches to achieving grain yield in wheat. Funct Integr Genomics 11:37-48 
Boudsocq M, Barbier-Brygoo H, Lauriere C (2004) Identification of nine sucrose nonfermenting 1-related protein kinases 2 activated by hyperosmotic and saline stresses in Arabidopsis thaliana. $\mathrm{J}$ Biol Chem 279:41758-41766

Brancourt-Hulmel M, Doussinault G, Lecomte C, Bérard P, Le Buanec B, Trottet M (2003) Genetic improvement of agronomic traits of winter wheat cultivars released in France from 1946 to 1992. Crop Sci 43:37

Braun HJ, Atlin G, Payne T, Reynolds MP (2010) Multi-location testing as a tool to identify plant response to global climate change. Eur J Neurosci 23:1129-1141

Canevara MG, Romani M, Corbellini M, Perenzin M, Borghi B (1994) Evolutionary trends in morphological, physiological, agronomical and qualitative traits of Triticum aestivum L. cultivars bred in Italy since 1900. Eur J Agron 3:175-185

Chang J, Zhang J, Mao X, Li A, Jia J, Jing R (2013) Polymorphism of TaSAP1-A1 and its association with agronomic traits in wheat. Planta 237:1495-1508

Coello P, Hey SJ, Halford NG (2011) The sucrose non-fermenting1-related (SnRK) family of protein kinases: potential for manipulation to improve stress tolerance and increase yield. J Exp Bot 62:883-893

Dong L, Wang F, Liu T, Dong Z, Li A, Jing R, Mao L, Li Y, Liu X, Zhang K, Wang D (2014) Natural variation of TaGASR7-Al affects grain length in common wheat under multiple cultivation conditions. Mol Breed 34:937-947

Gaju O, Reynolds MP, Sparkes DL, Foulkes MJ (2009) Relationships between large-spike phenotype, grain number, and yield potential in spring wheat. Crop Sci 49:961

Gedye KR, Gonzalez-Hernandez JL, Owens V, Boe A (2012) Advances towards a marker-assisted selection breeding program in prairie cordgrass, a biomass crop. Int J Plant Genomics 2012:313545

Guo Y, Sun J, Zhang G, Wang Y, Kong F, Zhao Y, Li S (2013) Haplotype, molecular marker and phenotype effects associated with mineral nutrient and grain size traits of TaGS1a in wheat. Field Crop Res 154:119-125

Gupta PK, Mir RR, Mohan A, Kumar J (2008) Wheat genomics: present status and future prospects. Int J Plant Genomics 2008:896451

Halford NG, Hey SJ (2009) Snf1-related protein kinases (SnRKs) act within an intricate network that links metabolic and stress signalling in plants. Biochem J 419:247-259

Hanif M, Gao F, Liu J, Wen W, Zhang Y, Rasheed A, Xia X, He Z, Cao S (2016) TaTGW6-A1, an ortholog of rice TGW6, is associated with grain weight and yield in bread wheat. Mol Breed 36:1

Hao C, Dong Y, Wang L, You G, Zhang H, Ge H, Jia J, Zhang X (2008) Genetic diversity and construction of core collection in Chinese wheat genetic resources. Sci Bull 53:1518-1526

Hao CY, Perretant MR, Choulet F, Wang LF, Paux E, Sourdille P, Zhang XY, Feuillet C, Balfourier F (2010) Genetic diversity and linkage disequilibrium studies on a 3.1-Mb genomic region of chromosome 3B in European and Asian bread wheat (Triticum aestivum L.) populations. Theor Appl Genet 121:1209-1225

Hardie DG (2007) AMP-activated/SNF1 protein kinases: conserved guardians of cellular energy. Nat Rev Mol Cell Biol 8:774-785

He Z, Rajaram S, Xin ZY, Huang GZ (2001) A history of wheat breeding China. CIMMYT, Mexico

Hrabak EM, Chan CW, Gribskov M, Harper JF, Choi JH, Halford N, Kudla J, Luan S, Nimmo HG, Sussman MR, Thomas M, WalkerSimmons K, Zhu JK, Harmon AC (2003) The Arabidopsis CDPKSnRK superfamily of protein kinases. Plant Physiol 132:666-680

Jiang Q, Hou J, Hao C, Wang L, Ge H, Dong Y, Zhang X (2011) The wheat (T. aestivum) sucrose synthase 2 gene (TaSus2) active in endosperm development is associated with yield traits. Funct Integr Genomics 11:49-61
Kuchel H, Williams KJ, Langridge P, Eagles HA, Jefferies SP (2007) Genetic dissection of grain yield in bread wheat. I. QTL analysis. Theor Appl Genet 115:1029-1041

Kulik A, Wawer I, Krzywinska E, Bucholc M, Dobrowolska G (2011) SnRK2 protein kinases-key regulators of plant response to abiotic stresses. J Integr Biol 15:859-872

Lata C, Muthamilarasan M, Prasad M (2015) Drought stress responses and signal transduction in plants. In: Girdhar KP (ed) Elucidation of abiotic stress signalling in plants: functional genomics perspectives. Springer, Berlin, pp 195-225

Li B, Li Q, Mao X, Li A, Wang J, Chang X, Hao C, Zhang X, Jing R (2016) Two novel AP2/EREBP transcription factor genes TaPARG have pleiotropic functions on plant architecture and yield-related traits in common wheat. Front Plant Sci 7:1191

Li H, Rasheed A, Hickey LT, He Z (2018) Fast-forwarding genetic gain. Trends Plant Sci 23:184-186

Livak KJ, Schmittgen TD (2001) Analysis of relative gene expression data using real-time quantitative PCR and the 2(-Delta Delta C(T)) method. Methods 25:402-408

Ludwig AA, Tina R, Jonathan DGJ (2003) CDPK-mediated signalling pathways: specificity and cross-talk. J Exp Bot 55:181-188

Ma D, Yan J, He Z, Wu L, Xia X (2012) Characterization of a cell wall invertase gene TaCwi-Al on common wheat chromosome $2 \mathrm{~A}$ and development of functional markers. Mol Breed 29:43-52

Ma L, Li T, Hao C, Wang Y, Chen X, Zhang X (2016) TaGS5-3A, a grain size gene selected during wheat improvement for larger kernel and yield. Plant Biotechnol J 14:1269-1280

Mao X, Zhang H, Tian S, Chang X, Jing R (2010) TaSnRK2.4, an SNF1-type serine/threonine protein kinase of wheat (Triticum aestivum L.), confers enhanced multistress tolerance in Arabidopsis. J Exp Bot 61:683-696

Maqbool R, Sajjad M, Khaliq I, Rehman AU, Khan AS, Khan SH (2010) Morphological diversity and traits association in bread wheat (Triticum aestivum L.). Am Eurasian J Agr Environ Sci $8: 216-224$

Mcintyre CL, Mathews KL, Rattey A, Chapman SC, Drenth J, Ghaderi M, Reynolds M, Shorter R (2010) Molecular detection of genomic regions associated with grain yield and yield-related components in an elite bread wheat cross evaluated under irrigated and rainfed conditions. Theor Appl Genet 120:527-541

Miao L, Mao X, Wang J, Liu Z, Zhang B, Li W, Chang X, Reynolds M, Wang Z, Jing R (2017) Elite haplotypes of a protein kinase gene TaSnRK2.3 associated with important agronomic traits in common wheat. Front Plant Sci 8:368

Mickelbart MV, Hasegawa PM, Bailey-Serres J (2015) Genetic mechanisms of abiotic stress tolerance that translate to crop yield stability. Nat Rev Genet 16:237-251

Murat F, Pont C, Salse J (2014) Paleogenomics in Triticeae for translational research. Curr Plant Biol 1:34-39

Nasu S, Suzuki J, Ohta R, Hasegawa K, Yui R, Kitazawa N, Monna L, Minobe Y (2002) Search for and analysis of single nucleotide polymorphisms (SNPs) in rice (Oryza sativa, Oryza rufipogon) and establishment of SNP markers. DNA Res 9:163-171

Rasheed A, Hao Y, Xia X, Khan A, Xu Y, Varshney RK, He Z (2017) Crop breeding chips and genotyping platforms: progress, challenges, and perspectives. Mol Plant 10:1047-1064

Rasheed A, Ogbonnaya FC, Lagudah E, Apples R, He Z (2018) The goat grass genome's role in wheat improvement. Nat Plant 4:56-58

Ray DK, Ramankutty N, Mueller ND, West PC, Foley JA (2012) Recent patterns of crop yield growth and stagnation. Nat Commun 3:1293

Reynolds M, Foulkes MJ, Slafer GA, Berry P, Parry MA, Snape JW, Angus WJ (2009) Raising yield potential in wheat. J Exp Bot 60:1899-1918 
Sajjad M, Ma X, Habibullah Khan S, Shoaib M, Song Y, Yang W, Zhang A, Liu D (2017) TaFlo2-A1, an ortholog of rice Flo2, is associated with thousand grain weight in bread wheat (Triticum aestivum L.). BMC Plant Biol 17:164

Semagn K, Babu R, Hearne S, Olsen M (2014) Single nucleotide polymorphism genotyping using kompetitve allele specific PCR (KASP): overview of the technology and its application in crop improvement. Mol Breed 33:1-14

Shearman VJ, Bradley RS, Scott RK, Foulkes MJ (2005) Physiological processes associated with wheat yield progress in UK. Crop Sci 45:175-185

Sreenivasulu N, Schnurbusch T (2012) A genetic playground for enhancing grain number in cereals. Trends Plant Sci 17:91-101

Stewart JR, Via LE (1993) A rapid CTAB DNA isolation technique useful for RAPD fingerprinting and other PCR applications. Biotechniques 14:748

Su Z, Hao C, Wang L, Dong Y, Zhang X (2011) Identification and development of a functional marker of TaGW2 associated with grain weight in bread wheat (Triticum aestivum L.). Theor Appl Genet 122:211-223

Tian S, Mao X, Zhang H, Chen S, Zhai C, Yang S, Jing R (2013) Cloning and characterization of TaSnRK2.3, a novel SnRK2 gene in common wheat. J Exp Bot 64:2063-2080

Vlad F, Rubio S, Rodrigues A, Sirichandra C, Belin C, Robert N, Leung J, Rodriguez PL, Lauriere C, Merlot S (2009) Protein phosphatases 2C regulate the activation of the Snf1-related kinase OST1 by abscisic acid in Arabidopsis. Plant Cell 21:3170-3184

Wang S, Wu K, Yuan Q, Liu X, Liu Z, Lin X, Zeng R, Zhu H, Dong G, Qian Q, Zhang G, Fu X (2012) Control of grain size, shape and quality by $O s S P L 16$ in rice. Nat Genet 44:950-954

Wang Q, Mao X, Xiaoping C, Jia J, Liu H, Jing R (2014) Polymorphism of TaSnRK2.10 and its association with yield related traits in wheat. Sci Agric Sin 47:1865-1877

Wrzaczek M, Hirt H (2001) Plant MAP kinase pathways: how many and what for? Biol Cell 93:81-87

Wu X, Chang X, Jing R (2012) Genetic Insight into yield-associated traits of wheat grown in multiple rain-fed environments. PLoS ONE 7:e31249

Zhang XY, Li CW, Wang LF, Wang HM, You GX, Dong YS (2002) An estimation of the minimum number of SSR alleles needed to reveal genetic relationships in wheat varieties. I. Information from large-scale planted varieties and cornerstone breeding parents in Chinese wheat improvement and production. Theor Appl Genet 106:112-117

Zhang H, Mao X, Jing R (2011a) SnRK2 acts within an intricate network that links sucrose metabolic and stress signaling in wheat. Plant Signal Behav 6:652-654

Zhang H, Mao X, Jing R, Chang X, Xie H (2011b) Characterization of a common wheat (Triticum aestivum L.) TaSnRK2.7 gene involved in abiotic stress responses. J Exp Bot 62:975-988

Zhang D, Hao C, Wang L, Zhang X (2012a) Identifying loci influencing grain number by microsatellite screening in bread wheat (Triticum aestivum L.). Planta 236:1507-1517

Zhang L, Zhao YL, Gao LF, Zhao GY, Zhou RH, Zhang BS, Jia JZ (2012b) TaCKX6-D1, the ortholog of rice OsCKX2, is associated with grain weight in hexaploid wheat. New Phytol 195:574-584

Zhang K, Wang J, Zhang L, Rong C, Zhao F, Peng T, Li H, Cheng D, Liu X, Qin H, Zhang A, Tong Y, Wang D (2013) Association analysis of genomic loci important for grain weight control in elite common wheat varieties cultivated with variable water and fertiliser supply. PLoS ONE 8(3):e57853

Zhang Y, Liu J, Xia X, He Z (2014) TaGS-D1, an ortholog of rice $O s G S 3$, is associated with grain weight and grain length in common wheat. Mol Breed 34:1097-1107

Zhang H, Li W, Mao X, Jing R, Jia H (2016) Differential activation of wheat SnRK2 family by abiotic stresses. Front Plant Sci 7:420

Zhang ZG, Lv GD, Li B, Wang JJ, Zhao Y, Kong FM, Guo Y, Li SS (2017) Isolation and characterization of the TaSnRK2.10 gene and its association with agronomic traits in wheat (Triticum aestivum L.). PLoS ONE 12:e174425

Zhou Y, He ZH, Sui XX, Xia XC, Zhang XK, Zhang GS (2007a) Genetic improvement of grain yield and associated traits in the northern China winter wheat region from 1960 to 2000. Crop Sci 47:245

Zhou Y, Zhu HZ, Cai SB, He ZH, Zhang XK, Xia XC, Zhang GS (2007b) Genetic improvement of grain yield and associated traits in the southern China winter wheat region: 1949 to 2000. Euphytica $157: 465-473$ 